\title{
Transport, climate change and society
}

\author{
Robin Hickman
}

Transport and climate change

London faces huge challenges in moving to a reduced reliance on oil and lower carbon dioxide $\left(\mathrm{CO}_{2}\right)$ emissions in its transport system and travel behaviours. The city is one of the most progressive internationally, at least in policy terms, in seeking to respond to climate change. It has a very high public transport mode share for radial trips to the central area, but is still heavily reliant on the private motor car (almost exclusively powered by petrol or diesel) for travel in the suburbs ${ }^{1}$.

The Mayor of London has set a very demanding target on climate change: a $60 \%$ reduction in $\mathrm{CO}_{2}$ emissions by 2025, across all sectors, on a 1990 baseline (Greater London Authority, 2007). Although there is no specific target in the transport sector, the expectation is that transport should make a significant contribution. The scale of the target set is consistent with the aspiration to limit the increase in global surface temperatures to $2^{\circ} \mathrm{C}$, at most, relative to present day levels (Intergovermental Panel on Climate Change, 2007; Stern, 2009). There is, however, less certainty as to how to achieve this target in terms of the level of investment required and the ability to influence individual travel behaviours. The response to climate change also neatly correlates with the oil scarcity problem. Many of the solutions required, such as a much greater use of public transport, walking and cycling, also mean there is likely to be less reliance on the petrol-fuelled motor car as the main mode of travel. The International Energy Agency (2009) points towards the urgency of the problem: there are just

${ }^{1}$ For Greater London as a whole, the car accounts for $40 \%$ of daily journey stages, with most car usage in outer London. Walking accounts for $21 \%$, bus $18 \%$, Underground $10 \%$, and cycling $2 \%$ of journey stages. Public transport is, of course, very well utilised for commute trips into central London. Journey stages are defined as follows: a journey trip is a complete one-way movement from origin to destination by one person for a single purpose, comprising a number of 'stages', e.g. walk to the station, Underground trip, and walk to work is one trip and three stages (Transport for London, 2007).

How to cite this book chapter:

Hickman, R. 2013. Transport, climate change and society. In: Bell, S and Paskins, J. (eds.) Imagining the Future City: London 2062. Pp. 55-62. London: Ubiquity Press. DOI: http://dx.doi.org/10.5334/bag.h 
46 years left' of conventional oil consumption, assuming proven reserves and current consumption rates. Though there are additional and large reserves of unconventional oil, surely we should be considering in earnest what our transport futures could be like under very different external conditions. This chapter considers these issues in terms of the potential transport scenarios possible for London to 2062 , and the likely wider governmental and societal changes required if travel behaviours are to become less carbon intensive to any significant degree.

\section{Transport scenarios to 2062}

Scenario analysis allows the comparison of potential policy trajectories, including possible trendbreaks away from the 'business as usual' (BAU) pathway to something more akin to a sustainable travel future. Each scenario includes a variety of policy measures, including different levels of 'application' (covering policy initiative, investment and approach to implementation). Scenarios can be developed by considering the major drivers of change affecting transport in London. These are given in Table 1 . Some are fairly certain in outcome, or at least well researched and understood as to their likely impact (e.g. demographic change). Others are more uncertain (e.g. the extent of increased environmental awareness and changed behaviours in the population). Many of the drivers have conflicting impacts in terms of likely travel distance, mode share and consumer choice.

Many of these trends can have dramatic impacts on travel patterns in London in future years, certainly over the long term to 2062. Figure 1 illustrates transport scenarios in London using a classic scenario 'dilemma' matrix (drawing on the approach from Schwartz (1996) and Van der Heijden (1996)). Two of the major issues from the drivers of change, in this case the extent of technological change and environmental stewardship, are used to generate the dimensions of change within the scenarios. These are chosen to highlight the major problem currently facing transport planners in London (and indeed the wider UK and international arena): whether the gains in vehicle efficiency with cleaner vehicles can allow us to remain as mobile as we are, or become even more mobile, with use of a similar mode share; or whether travel behaviours need to change markedly as well as the vehicles. Do we need to rely on more than technological change, and to think through how to change travel behaviours more effectively than we do at present?

\begin{tabular}{|c|c|}
\hline Emerging Socio-Demographic Trends & Potential Travel Implications \\
\hline $\begin{array}{l}\text { - Changing demographic and household structures } \\
\text { - Increasing world trade and globalisation } \\
\text { - Economic volatility, including periods of financial } \\
\text { collapse and recovery } \\
\text { - Rising importance of local activity provision, but } \\
\text { greater discernment in choice of activities and con- } \\
\text { sumer purchases } \\
\text { - Rapid technological developments and the emer- } \\
\text { gence of 'digital natives' (the new generation growing } \\
\text { up accustomed to the use of technology) } \\
\text { - Taxation increasingly based on resource and energy } \\
\text { consumption rather than income } \\
\text { - Decline in the power of national governments and } \\
\text { distrust in institutions (with a reduced ability to } \\
\text { influence change) } \\
\text { - Increasing awareness of sustainability issues and } \\
\text { demand for change in opportunities and lifestyles }\end{array}$ & $\begin{array}{l}\text { - Steady increase in demand for mobility, particularly } \\
\text { long distance and with speedy modes - for pas- } \\
\text { sengers and goods; with periods of reduced growth } \\
\text { related to economic volatility } \\
\text { - Huge growth in demand for public transport, } \\
\text { walking and cycling, as environmental and health } \\
\text { benefits become much more widely known and } \\
\text { sought after } \\
\text { - Increased importance of and attention to the quality } \\
\text { of the journey experience } \\
\text { - Aggregate travel times remain steady } \\
\text { - Gradual increase in share of low emission vehicles } \\
\text { and use of alternative fuels } \\
\text { - Increased trip distances in goods movement; though } \\
\text { partial reduction through localised sourcing } \\
\text { - Much greater realisation of the 'Network Society' - } \\
\text { electronic flows replace part of physical travel as well } \\
\text { as opening up a new range of social interactions }\end{array}$ \\
\hline
\end{tabular}

(Developed from the Department for Trade and Industry and Office of Science and Technology, 2006)

Table 1: Drivers of Change. 


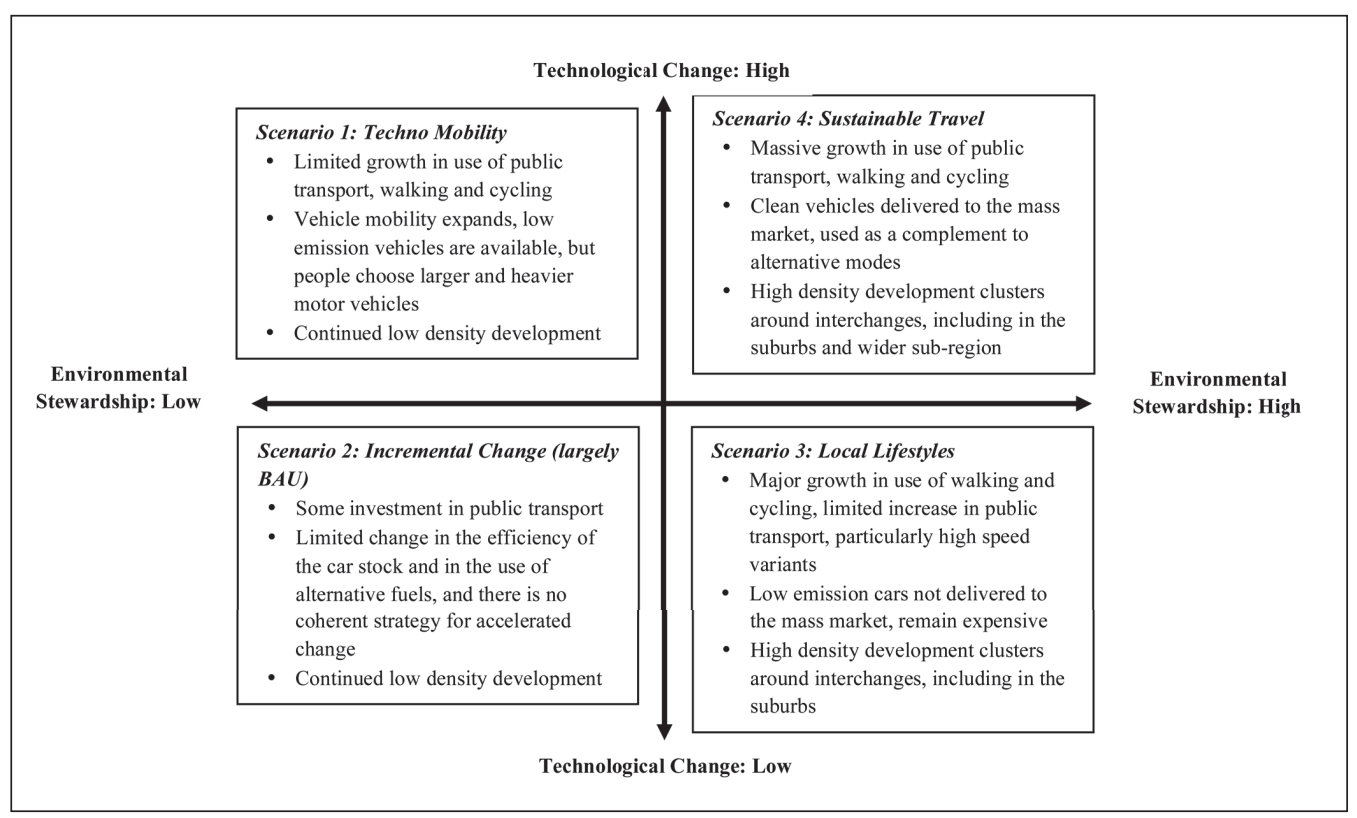

Figure 1: Potential Transport Futures 2062.

\section{Governance and societal implications}

Clearly there are multiple potential futures in transport, four of which have been described above. Some are more preferable than others. All, with perhaps the exception of the current incremental change 'BAU', are likely to prove difficult in implementation terms. This is a major problem politically: governments have notorious difficulties in moving public behaviours away from the mainstream trends. The recent political progression in the UK, at the national level, has been towards a neoliberal viewpoint. Individual 'choice' is protected as the primary interest, and 'governmental intervention' perceived as difficult and unwarranted. For example, there is a tendency to rely on the 'nudge' in policy making, drawing on the work of Thaler and Sunstein (2008), rather than more interventionist approaches. This strategy, of course, is very unlikely to reduce transport $\mathrm{CO}_{2}$ emissions to any significant degree. This key point is either overlooked or ignored, depending on the acceptance of the RealPolitik and Greenwash ${ }^{2}$ reading of events.

In London, an ambitious policy and investment programme has been developed in transport, with a series of major transport projects developed. But, even where the ambition is greater, where there is a seemingly well developed future strategy, there are often large difficulties in implementation, both in terms of political deliverability and public acceptability. These issues can be explored using the concepts of policy discourse and 'discourse coalitions'. The current dominant governmental process in London can be viewed as reflecting the 'environmental management' approach, where the sustainability problem is seen as a fundamental failure in the workings of the institutions of society, yet the solution is seen as a combined 'techno-institutional fix', and importantly using the current institutional arrangements, i.e. a little better regulation will suffice (Hajer, 1995).

2 'RealPolitik': the politics and policy development based primarily on power and on practical considerations, rather than valued notions or ethical premise. The term can be linked to the practice of 'Greenwashing', whereby the conjecture in policy making concerns environmental sustainability, but little is ever done in terms of actual investment and policy initiative. 
This is a narrow conceptualisation of the potential options for policy delivery, of power and power relations, and different potential pathways to achieve societal goals. The framing and definition of the problem and solution is thus very important.

The more critical observers argue that the mainstreamed use of 'sustainability' as a concept has been a 'rhetorical effort' concealing a strategy for sustainable development, but with the emphasis strongly in supporting gross domestic product (GDP) growth and profit maximisation, at the expense of environmental and social policy goals, and ignoring the basic contradictions that are evident within the sustainability concept. Thus, the conventional storyline attempts to 'reconcile the irreconcilable' (in this case, the environment and development) (Hajer, 1995; Jackson, 2009). These types of issues are evident in the transport sector in London. The London Plan offers a progrowth paradigm, and there is little effort to radically reduce travel distance and change mode share in London, particularly in the suburbs. Individuals and organisations within London and the UK have widely differing views as to what 'sustainable travel' or 'sustainable cities' might mean. Take, for example, the King Review (King, 2008) and the Eddington Study (Eddington, 2006), where the focus was on improving the delivery of low emission vehicles, supporting long distance travel (by air, motor car and high speed rail); or the environmental group lobby, where the call is for a much greater use of short distance travel, inter and intra-urban based public transport, and walking and cycling. Many of these actors postulate that they are trying to achieve greater 'sustainability' in travel behaviours. But there is often little in terms of shared values or common interests, and people are working to different definitions of the 'sustainable travel' concept.

So we have a messy and confused understanding and application of the sustainability concept in transport. Few actors in the sustainable transport field appear to have developed a radical social critique; it is assumed that very radical targets can be achieved within the same institutional system. However, this is far from clear from the evidence and the current trends. The transition to sustainable transport does not appear to be a 'value free' process of convincing various actors of the importance of 'the green case. The history is much more of a 'struggle' between different coalitions of interests and beliefs, each consisting of and supported by scientists, politicians, activists, research groups, lobbyists, marketing and advertising groups, newspapers, film, $\mathrm{TV}$, journals, trade press, and even celebrities. If examined closely, the various groups are very fragmented and contradictory. Each group develops and supports its own particular discourse, a particular way of thinking and talking about sustainability. Some develop momentum and influence, others fade from view (Hajer, 1995). At the individual level, we also act upon our own 'images of reality', drawing on certain discourses that we engage in or are engaged with. We may think that our choice of travel and its impact on the environment is limited, that our lifestyles are fairly fixed, that it is 'too difficult' to move away from car based mobility given complex lives, that public transport is too expensive to provide to the mass market beyond the urban centres, and that we can do little to reduce $\mathrm{CO}_{2}$ emissions in the transport field. This is certainly the dominant discourse, but there are of course many others, some differing in view and action, and some significantly so.

In London, the policy measures being employed are relatively progressive, and compare very well to practice elsewhere internationally. There is a congestion charge (introduced in 2003), albeit for a small part of central London (and reduced in area coverage since the removal of the western extension), charging $£ 10$ for vehicles to enter the cordon. There are many impressive investments in public transport, either recent or planned, such as the Jubilee Line extension (opened 1999); London Overground, an orbital rail link around suburban London (the first sections were established in 2007); some state-of-the-art interchange redevelopments, such as King's Cross/St Pancras (the refurbishment opened 2012); and Crossrail, a major new east-west railway link across central London (scheduled to open in 2018). However, even with these measures, it is unlikely that transport $\mathrm{CO}_{2}$ emissions in London will reduce by anything near $60 \%$ by 2025 on 1990 levels. The 
current Transport for London approach is only likely to reduce transport emissions in the order of 20-25\% (Hickman et al, 2009). The critical 'discontinuity' measures, i.e. those that make a significant difference, are not being implemented to any degree. Perhaps this is with good reason: there is little public understanding of the scale of change required to reduce transport $\mathrm{CO}_{2}$ emissions by $60 \%$, or deeper to $80 \%$ and, perhaps as a result, little political appetite.

To explore these issues further, the political possibility of delivering particular policy measures can be examined in terms of the degree of public authority (legitimate coercion) required to implement them (Dunn \& Perl, 2010). The level of 'coercion' is viewed as reflecting an element of 'forcing' another party to behave in a non-voluntary manner (through action or inaction). A 'weak state tradition', as increasingly experienced in the UK, means that policy tools are generally chosen from the least coercive part of the spectrum. Regulation on businesses and individuals results in hostile responses, intense lobbying and the 'watering down' of original proposals. Increased taxes, for example, begin to be viewed almost as 'legalised extortion'. Subsidies and voluntary schemes prove much more acceptable to politicians and the public, but of course only if maintained at a limited scale (Dunn \& Perl, 2010). Again, this framing of the debate is critical. Many of the measures that would make a difference to reducing transport $\mathrm{CO}_{2}$ emissions are also the ones that are perceived as undeliverable politically in the current context. There is little chance of road pricing across the Greater London area. There are no great moves to increase densities in the suburbs. There are no plans to develop tram or bus rapid transit schemes in Outer London, to provide segregated facilities for cycling or a new series of public realm improvements, or to encourage with subsidy a large number of low emissions vehicles in the London fleet. All of these types of radical measures would be required to reduce $\mathrm{CO}_{2}$ emissions to a significant degree in London, to levels reaching the ambitious $60 \%$ reduction target.

The risk society thesis (Beck, 1992) suggests that the basis on which environmental politics have so far been made has to be fundamentally rethought. Climate change is not simply a problem that can be regulated away, and certainly not by the existing institutional arrangements. These have been successful in producing unprecedented wealth for a small cohort of the population, but this has occurred only with considerable social and environmental cost. Beck (1992) argues that the ecological crisis might become the 'stepping stone' to a new and superior form of modernity. But the existing institutions are 'digging their own grave' by increasingly showing their inability to handle the dangers they have themselves produced. Though London is progressive relative to most other contexts, the Beck thesis still seems to stand. Many of the policy approaches being considered, and implemented, are having little impact against the strategic targets being set at the city level. Almost all public observers demand more progress in moving towards lower $\mathrm{CO}_{2}$ emissions. Scenario 4 (Sustainable Travel), as developed earlier, is perhaps what policy makers would like to deliver, but it is not at all clear that this level of environmental stewardship, even in London, is being achieved. The level of investment in public transport and the other non-car modes has not changed to the expected degree. In the end, we do not seem to be moving far away from Scenario 2 (Incremental Change).

This intractable conflict is hidden in the initial definition of the problem, in the issues discussed and those that remain undiscussed. The framing of the debate makes certain elements seem 'fixed' and inappropriate, others are viewed as 'problematic', and some much easier to discuss and 'deliver' (Hajer, 1995; Hickman \& Banister, 2013). The classic examples in transport are measures such as road pricing, reducing space for private cars, increasing densities in suburban areas, and, of course, reducing the growth in international air travel: all of these are seen as 'politically difficult' and usually remain beyond the mainstream debate. These are debated as seemingly 'technical' positions, but of course conceal a normative stance, supported by the institutional arrangements (Hajer, 1995). The contest between development, travel and sustainability is often an ideological one, rooted in fundamentally different value systems and worldviews, and 
is closely linked to our consumption-based society (Urry, 2007). It is unlikely that we can meet $\mathrm{CO}_{2}$ reduction targets and aspirations to reduce climate change whilst pursuing the consumerism model (Wheeler, 2012). This is inherently problematic and does not seem to be understood or even debated. Debord (1967) asks that we 'wake up the spectator who has been drugged by spectacular images'. This appears very relevant still: there is an opportunity, but it is a narrowing window of opportunity, and perhaps, as yet, there is little appetite to tackle the fundamental issues to any significant degree. Much like Plato's Allegory of the Cave (Plato, 380), we have lived chained to our car and oil dependency for the major part of our lives. We have ascribed forms to the lifestyle, believing that it brings freedom, status and even expression, but in reality there are many hugely adverse impacts that we continue to ignore. We (simply) need to realise that there are much more attractive travel lifestyles on offer: who wouldn't want to commute, Copenhagen-style, by bicycle; to use the French-style trams in the suburban centres; to use our electric hybrids whenever we need to use the car? We just need to look outside to the sunshine - but it seems the real debate is very slow to develop: to consider how transport is important to the development of the city and to society itself, and how the shaping of society and its institutions affect our travel.

\section{References}

Beck U. 1992. Risk Society: Towards a New Modernity. London: Sage

Debord G. 1967. Society of the Spectacle [first published as La Société du Spectacle by BuchetChastel, 1967]. Eastbourne: Soul Bay Press. Reprinted 2009

Department for Trade and Industry and Office of Science and Technology. 2006. Intelligent Infrastructure Systems. Project Overview. London: DTI and OST

Dunn J. and Perl A. 2010. Launching a post carbon regime for American surface transportation: Assessing the policy tools. Lisbon: World Conference on Transport Research

Eddington R. 2006. The Eddington Transport Study [Rod Eddington]. HM Treasury. Norwich: The Stationery Office

Greater London Authority. 2007. Climate Change Action Plan. London: GLA.

Hajer M. 1995. The Politics of Environmental Discourse: Ecological Modernization and the Policy Process. Oxford: Clarendon Press

Hickman R, Ashiru O. and Banister D. 2009. Visioning and Backcasting for Transport in London (VIBAT-London). Stages 1-4, Background Reports. London: Halcrow Group

Hickman R. and Banister D. 2013. Transport, Climate Change and the City. Abingdon: Routledge

Hood C. 1986. Administrative Analysis: An Introduction to Rules, Enforcement and Organisations.

New York: St Martins Press

International Energy Agency. 2009. Transport Energy and CO2. Paris: IEA

Intergovermental Panel on Climate Change. 2007. Fourth Assessment Report on Climate Change.

In: Synthesis Report. Geneva: IPCC

Jackson T. 2009. Prosperity Without Growth: Economics for a Finite Planet. London: Earthscan

King J. 2008. The King Review of Low Carbon Cars [Julia King]. Part 2: Recommendations for Action, HM Treasury. Norwich: The Stationery Office

Plato. 380 BC. The Republic. Reprinted 2007. In: Lee H. and Lane M, editors. London: Penguin

Schwartz P. 1996. The Art of the Long View: Paths to Strategic Insight for Yourself and Your Company. London: Currency Doubleday

Stern N. 2009. A Blueprint for a Safer Planet: How to Manage Climate Change and Create a New Era of Progress and Prosperity. London: Bodley Head

Thaler R. and Sunstein C. 2008. Nudge: Improving Decisions About Health, Wealth, and Happiness. New Haven: Yale 
Transport for London. 2007. Travel in London. London: Transport for London Urry J. 2007. Mobilities. Cambridge: Polity

Van Der Heijden K. 1996. Scenarios: The Art of Strategic Conversation. Chichester: John Wiley Wheeler S. 2012. Climate Change and Social Ecology: A New Perspective on the Climate Challenge. London: Routledge 


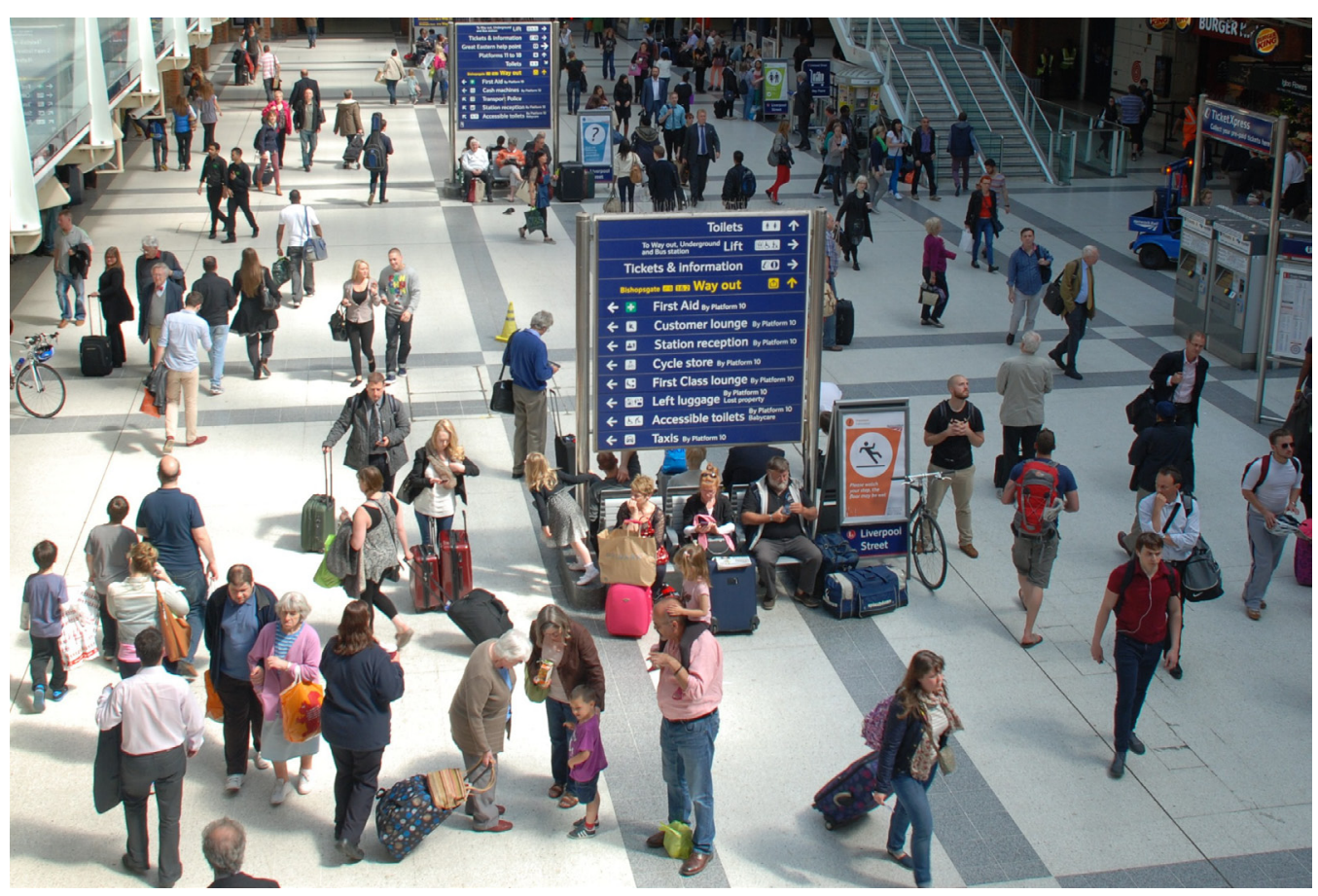

